\title{
Article \\ Surface Modification towards Integral Bulk Catalysts of Transition Metal Borides for Hydrogen Evolution Reaction
}

\author{
Wei Zhao ${ }^{1}$, Dan Xu ${ }^{1}$, Yanli Chen ${ }^{2, *(\mathbb{D} \text {, Jiaen Cheng }}{ }^{1}$, Cun You ${ }^{1}$, Xin Wang ${ }^{1}$, Shushan Dong ${ }^{1}$, Qiang Tao ${ }^{1, *(\mathbb{D})}$ \\ and Pinwen $\mathrm{Zhu}{ }^{1, *}$ \\ 1 State Key Laboratory of Superhard Materials, College of Physics, Jilin University, Changchun 130012, China; \\ zhaow18@mails.jlu.edu.cn (W.Z.); xudan@jlu.edu.cn (D.X.); chengje19@mails.jlu.edu.cn (J.C.); \\ youcun19@mails.jlu.edu.cn (C.Y.); xin_wang@jlu.edu.cn (X.W.); dongss@jlu.edu.cn (S.D.) \\ 2 Key Laboratory of Functional Materials Physics and Chemistry of the Ministry of Education, \\ Jilin Normal University, Changchun 130103, China \\ * Correspondence: ylchen@jlnu.edu.cn (Y.C.); qiangtao@jlu.edu.cn (Q.T.); zhupw@jlu.edu.cn (P.Z.)
}

Citation: Zhao, W.; Xu, D.; Chen, Y.; Cheng, J.; You, C.; Wang, X.; Dong, S.; Tao, Q.; Zhu, P. Surface Modification towards Integral Bulk Catalysts of Transition Metal Borides for Hydrogen Evolution Reaction. Catalysts 2022, 12, 222. https:/ / doi.org/10.3390/catal12020222

Academic Editor: Rahat Javaid

Received: 30 January 2022

Accepted: 14 February 2022

Published: 16 February 2022

Publisher's Note: MDPI stays neutral with regard to jurisdictional claims in published maps and institutional affiliations.

Copyright: (C) 2022 by the authors. Licensee MDPI, Basel, Switzerland. This article is an open access article distributed under the terms and conditions of the Creative Commons Attribution (CC BY) license (https:// creativecommons.org/licenses/by/ $4.0 /)$.

\begin{abstract}
Transition metal borides (TMBs) are promising catalysts for hydrogen evolution reaction (HER). While the commercially available TMBs indicate poor HER performance due to powder electrode and low activity sites density, optimizing commercial TMBs for better HER performance is urgent. To break through the challenge, a new strategy is proposed to compose integral bulk electrodes with needle surfaces in TMBs. The integral bulk electrodes in $\mathrm{TiB}_{2}, \mathrm{ZrB}_{2}$, and $\mathrm{HfB}_{2}$ are formed under high pressure and high temperature (HPHT), and the nanoneedle morphology is constructed by chemical etching. In the three materials, the smallest overpotential is $346 \mathrm{mV}$ at $10 \mathrm{~mA} \mathrm{~cm}^{-2}$ in the $\mathrm{HCl}$ etched bulk $\mathrm{TiB}_{2}$ electrode, which is about $61.9 \%$ higher than commercial $\mathrm{TiB}_{2}$ powder. Better performance arises from better conductivity of the integral bulk electrode, and the nano morphology exposes the edge sides of the structure which have high activity site density. This work is significant for developing new kinds of bulk TMBs catalysts.
\end{abstract}

Keywords: transition metal borides; integral bulk catalysts; surface modification; high pressure and high temperature; electrocatalyst; hydrogen evolution reaction

\section{Introduction}

Hydrogen is a promising renewable energy candidate to replace conventional energy sources because of its high energy density and zero greenhouse gas emissions [1-5]. Water electrolysis is an ideal way to obtain highly pure hydrogen [6-8]. Suitable electrocatalysts can effectively improve hydrogen production and reduce overpotential [9]. Up to now, precious metal platinum-based materials are the most active electrocatalysts for hydrogen evolution reaction (HER), which have the lowest overpotential and Tafel slope [10]. However, the commercialization of water electrolysis is hampered due to precious metal electrocatalysts with high prices and scarce availability [11-14]. Thus, developing noble metal-free electrocatalysts is necessary.

In the past few decades, noble metal-free electrocatalysts including sulfides, carbides, phosphides, nitrides and alloys were extensively studied [15-20]. Among them, transition metal borides (TMBs) are favored by researchers because of their structural diversity, excellent electrical properties and stability. Mo-B, Ni-B, Co-B and Fe-B have shown excellent HER performance [21-28]. Meanwhile, commercially available TMBs are mostly sintered at high temperatures at present, which can exhibit the intrinsic catalytic performance of TMBs. However, many commercial TMBs exhibit poor HER performance because of their micron grain size, which is easy to fall off when preparing catalytic electrodes during HER and will hinder the exposure of activity sites $[29,30]$. Moreover, the Nafion adhesive can cause huge contact resistance between particles and electrodes, which impedes the development of 
TMBs catalysts $[23,31]$. Therefore, modifying TMBs and inventing a new kind of electrode is necessary.

Exploring integral bulk electrodes in TMBs for HER is an effective way to eliminate contact resistance. They are comparable with self-supported electrodes, which have excellent charge transport. However, it is difficult to obtain the dense bulk TMBs because of their high melting point and low diffusion coefficient. High pressure and high temperature (HPHT) is a key route to densify and modify TMBs. HPHT can effectively reduce the reaction temperature and reaction time under certain pressure and promote the densification of TMBs. More and more TMBs bulk are successfully synthesized by the HPHT method [32-35]. Therefore, HPHT is a suitable method to fabricate integral bulk electrodes. Besides, the $\mathrm{AlB}_{2}$-type TMBs are promising catalysts. Although $\alpha-\mathrm{MoB}_{2}$ has the best HER performance, it cannot be purchased due to its high synthesis temperature of $1800^{\circ} \mathrm{C}$ [23]. However, $\mathrm{TiB}_{2}, \mathrm{ZrB}_{2}$ and $\mathrm{HfB}_{2}$ are commercially available, and the transition metals of Ti, $\mathrm{Zr}, \mathrm{Hf}$ are in the same group. Therefore, commercial $\mathrm{TiB}_{2}, \mathrm{ZrB}_{2}$ and $\mathrm{HfB}_{2}$ are suitable to design integral bulk electrodes.

Although the integral bulk electrode has excellent conductivity, the disadvantage is that the sample is bulky with a smaller surface area. As is known to all, the surface area of electrocatalysts can affect the number of active sites exposed, which directly dominates the catalyst performance. Typically, the bulk $\mathrm{MoS}_{2}$ has no HER performance, while nanosized $\mathrm{MoS}_{2}$ shows excellent catalytic activity [36]. Most of the high-performance electrocatalysts reported are nanosized at present [37]. Nano-morphology construction on the surface of TMBs is the key to further improving its electrocatalysts performance. Nevertheless, surface modification to form nano-morphology in bulk TMBs is a challenge because TMBs always have strong covalent bonds, which is difficult to process [38]. Moreover, the activity sites are located at some specific crystal planes thus surface modification should better expose the active crystal planes. Therefore, one strategy to achieve high HER performance in TMBs is composing integral bulk electrodes with nano morphology which exposes the active crystal planes.

To solve the above problems, in this work, commercially purchased $\mathrm{AlB}_{2}$-type TMBs $\left(\mathrm{TiB}_{2}, \mathrm{ZrB}_{2}, \mathrm{HfB}_{2}\right)$ were densified by HPHT to obtain an integral bulk electrode. Then, chemical etching was used to construct the nanomorphology on the surface for the modified sample. The changes of the structure, morphology and valence state of the modified sample before and after nano-construction were studied, as well as the influence on HER performance. The theoretical calculation was used to analyze the internal mechanism of catalytic activity.

\section{Results and Discussion}

The initial transition metal borides (TMBs) were purchased commercially. The crystal structure and purity of the material were analyzed by X-ray diffraction (XRD) (Figure S1). The intensity and position of the diffraction peaks indicate that the purchased initial powders are pure phase $\mathrm{TiB}_{2}, \mathrm{ZrB}_{2}$ and $\mathrm{HfB}_{2}$ (PDF card 85-2083, 65-8704 and 65-8677). The polarization curves of HER for initial powders catalysts are recorded in Figure S2. The overpotential of initial $\mathrm{TiB}_{2}, \mathrm{ZrB}_{2}$ and $\mathrm{HfB}_{2}$ powder at a current density of $10 \mathrm{~mA} \mathrm{~cm}{ }^{-2}$ $\left(\eta_{10}\right)$ exceeds $900 \mathrm{mV}$, indicating poor HER performance. The poor HER performance may come from the large connect resistance of the micron size powder electrode. HPHT was performed to generate bulk electrodes under $5 \mathrm{GPa}$ and $1600{ }^{\circ} \mathrm{C}$. The crystallinity and phase purity of the bulk materials were characterized by XRD. As shown in Figure 1a, $\mathrm{TiB}_{2}, \mathrm{ZrB}_{2}$ and $\mathrm{HfB}_{2}$ after HPHT have highly intense peaks, which mean they are highly crystalline, and no impurities exist. All three materials have a hexagonal crystal system (space group $\mathrm{P6} / \mathrm{mmm}$ ) and belong to the $\mathrm{AlB}_{2}$-type structure, which is alternately stacked by close-packed transition metal atoms and borophene-likes layers (Figure 1b). 

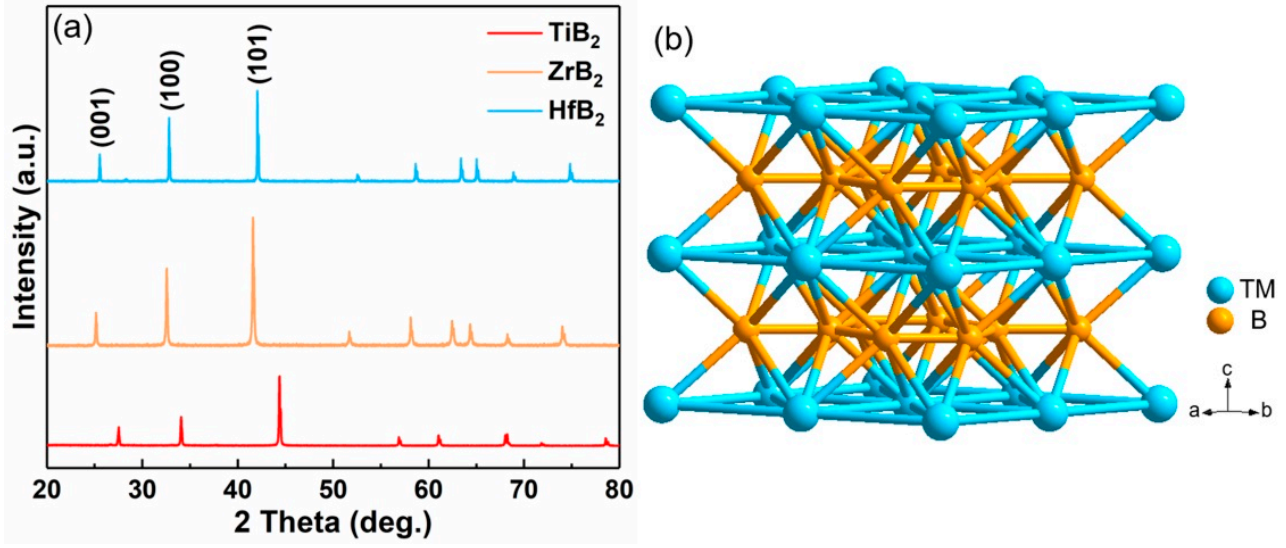

Figure 1. (a) The $\mathrm{XRD}$ of $\mathrm{TiB}_{2}, \mathrm{ZrB}_{2}$ and $\mathrm{HfB}_{2}$ modified by HPHT, and (b) the crystal structure of $\mathrm{AlB}_{2}$ type materials.

The bulk samples are composed of high-density micron-size grains, which benefit conductivity (Figure 2a-c). High-resolution transmission electron microscopy (HRTEM) is used to observe finer structural information. All these structures have good crystallinity in Figure 2d-f. The spacing of $0.266 \mathrm{~nm}$ and $0.320 \mathrm{~nm}$ corresponds to (100) and (001) crystal planes in $\mathrm{TiB}_{2}$. The spacing of $0.219 \mathrm{~nm}, 0.278 \mathrm{~nm}, 0.175 \mathrm{~nm}$ and $0.215 \mathrm{~nm}$ matched the (101), (100) and (002), (101) crystal planes in $\mathrm{ZrB}_{2}$ and $\mathrm{HfB}_{2}$, respectively. All of the results confirmed that integral bulk electrodes of $\mathrm{TiB}_{2}, \mathrm{ZrB}_{2}$ and $\mathrm{HfB}_{2}$ are formed after HPHT treatment.
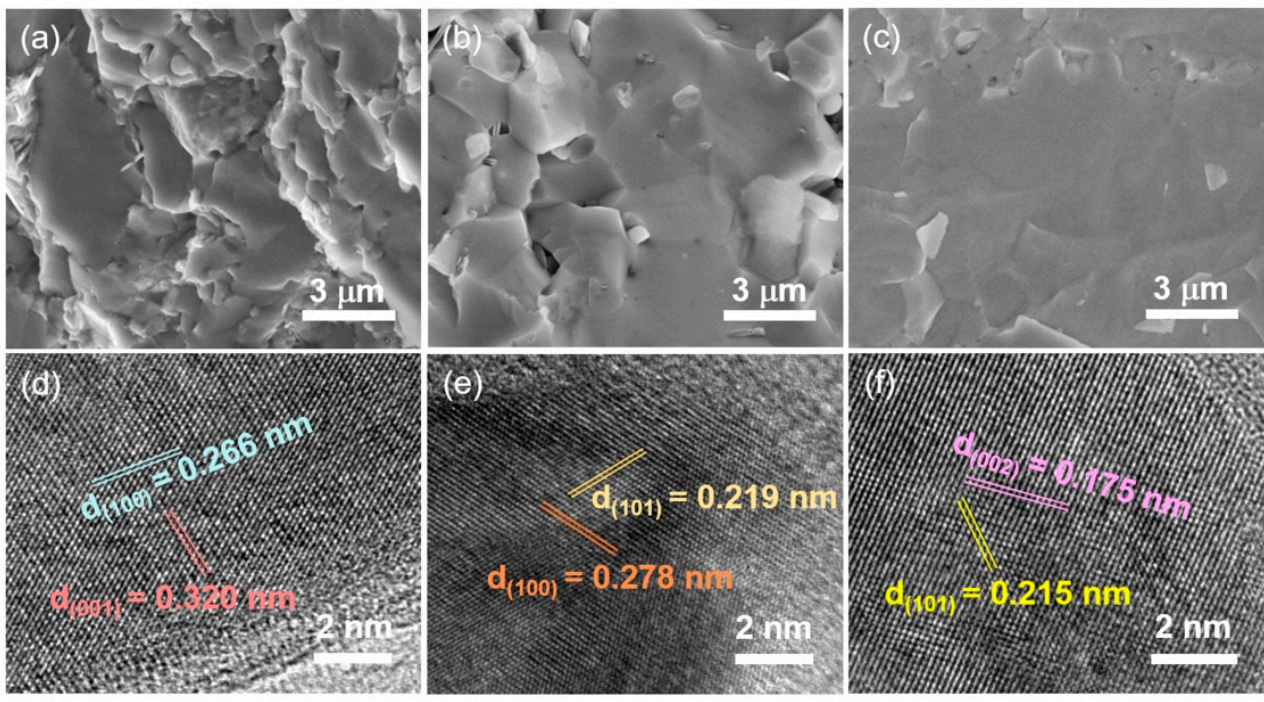

Figure 2. The SEM images of $(\mathbf{a}) \mathrm{TiB}_{2}$, (b) $\mathrm{ZrB}_{2}$ and (c) $\mathrm{HfB}_{2}$ after HPHT treatment, and the corresponding HRTEM images of (d) $\mathrm{TiB}_{2}$, (e) $\mathrm{ZrB}_{2}$ and (f) $\mathrm{HfB}_{2}$.

The electrochemical HER performance of $\mathrm{TiB}_{2}, \mathrm{ZrB}_{2}$, and $\mathrm{HfB}_{2}$ after $\mathrm{HPHT}$ employs a standard three-electrode system on $\mathrm{CH}$ Instruments $760 \mathrm{E}$ at the $0.5 \mathrm{M} \mathrm{H}_{2} \mathrm{SO}_{4}(\mathrm{pH} 0)$ electrolyte. As shown in Figure 3a, the overpotential of $\mathrm{TiB}_{2}, \mathrm{ZrB}_{2}$ and $\mathrm{HfB}_{2}$ after $\mathrm{HPHT}$ treatment are 477, 627 and $563 \mathrm{mV}$, respectively. The results indicated that the HER performance of the materials after HPHT treatment is greatly improved, and $\mathrm{TiB}_{2}$ showed the best HER activity. The corresponding Tafel slope is shown in Figure $3 \mathrm{~b}$. $\mathrm{TiB}_{2}$, after HPHT treatment, also has the lowest Tafel slope $\left(149.38 \mathrm{mV} \mathrm{dec}^{-1}\right)$, which means a faster catalytic reaction rate for HER under acidic conditions. Moreover, the charge transport resistance of different catalysts was studied by electrochemical impedance spectroscopy (EIS), and the Nyquist curves are shown in Figure 3c. The charge transport resistance of 
$\mathrm{TiB}_{2}$ is much smaller than that of $\mathrm{ZrB}_{2}$ and $\mathrm{HfB}_{2}$, indicating that the charge transfer between $\mathrm{TiB}_{2}$ electrode and electrolyte is more effective at the interface during HER action. At the same time, the electrochemical surface area (ECSA) can be evaluated with electrochemical double-layer capacitance $\left(C_{\mathrm{dl}}\right)$. Figure $3 \mathrm{~d}$ show the $\mathrm{C}_{\mathrm{dl}}$ value of $\mathrm{TiB}_{2}$ is $1.97 \mathrm{mF} \mathrm{cm}{ }^{-2}$, which is 3.4 and 5.3 times higher than $\mathrm{ZrB}_{2}$ and $\mathrm{HfB}_{2}$, respectively. It indicates that $\mathrm{TiB}_{2}$ has more catalytic active sites involved in the HER process. All of the results show that $\mathrm{TiB}_{2}$ has superior catalytic performance for HER.
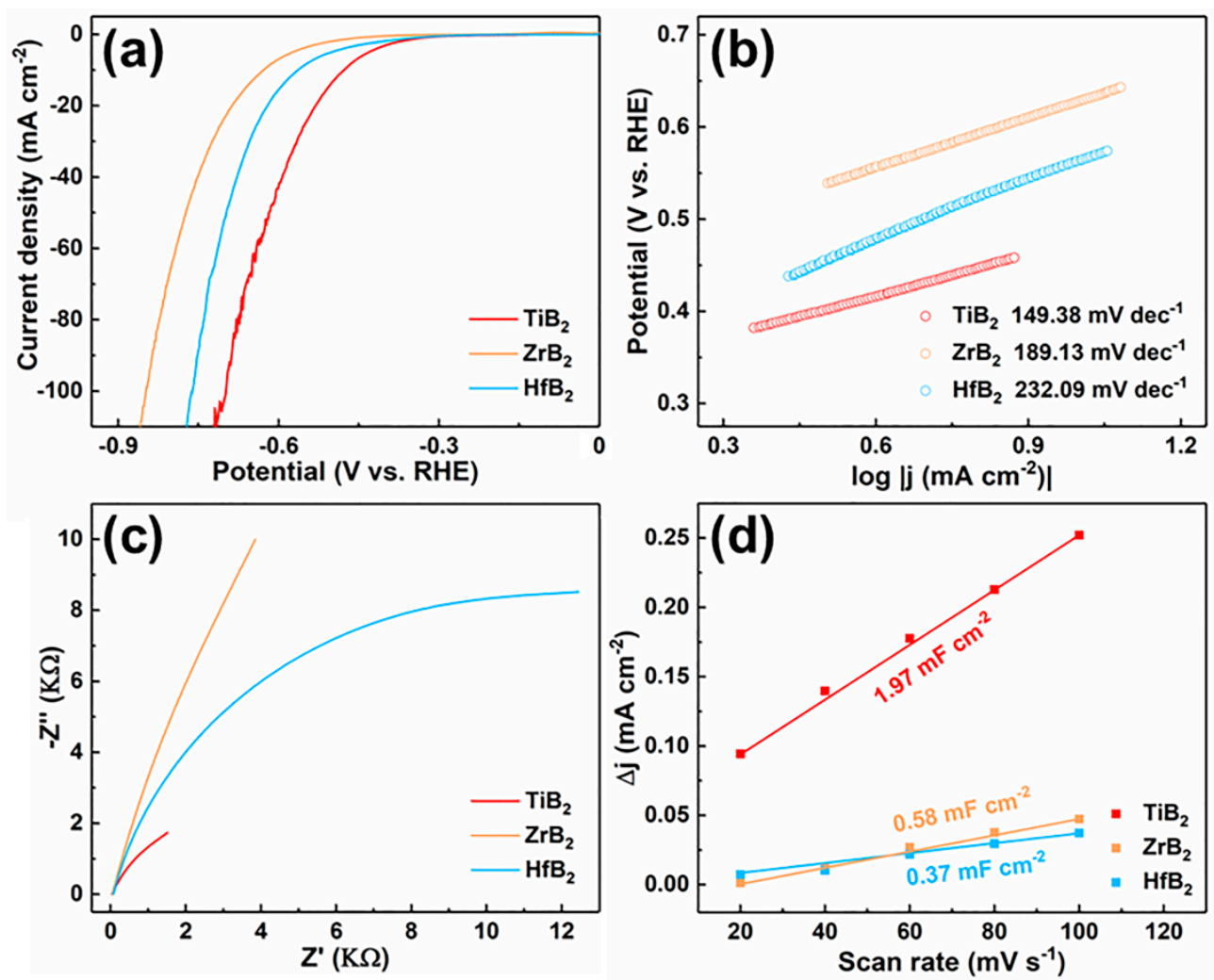

Figure 3. (a) The linear sweep voltammetry (LSV) curves of $\mathrm{TiB}_{2}, \mathrm{ZrB}_{2}$ and $\mathrm{HfB}_{2}$ after $\mathrm{HPHT}$ treatment for HER in $0.5 \mathrm{M} \mathrm{H}_{2} \mathrm{SO}_{4}$ solution, (b) Tafel slopes of $\mathrm{TiB}_{2}, \mathrm{ZrB}_{2}$ and $\mathrm{HfB}_{2}$ after HPHT treatment, (c) EIS Nyquist plots of $\mathrm{TiB}_{2}, \mathrm{ZrB}_{2}$ and $\mathrm{HfB}_{2}$ after HPHT treatment, (d) ECSA fitting curves of $\mathrm{TiB}_{2}, \mathrm{ZrB}_{2}$ and $\mathrm{HfB}_{2}$ after HPHT treatment.

The better HER performance of $\mathrm{TiB}_{2}, \mathrm{ZrB}_{2}$ and $\mathrm{HfB}_{2}$ after HPHT treatment, the more dense integral bulk electrode, which brings better conductivity and lowers connected resistance, while these bulk electrodes sacrifice specific area. As we know, these $\mathrm{TMB}_{2}$ are layer structures with anisotropic HER performance in different crystal planes [39-42]. To further improve the HER performance, it is desirous to fabricate nano surface morphology and expose the crystal plane with active sites.

To uncover the activity crystal planes with the high HER performance, the Gibbs free energy $(\Delta \mathrm{G})$ of $\mathrm{TiB}_{2}, \mathrm{ZrB}_{2}$ and $\mathrm{HfB}_{2}$ are calculated (Figure 4). The results indicate the crystal planes of $\mathrm{TiB}_{2}(100), \mathrm{ZrB}_{2}$ (100) and $\mathrm{HfB}_{2}(110)$ have the lowest $\Delta \mathrm{G}$. Additionally, all these structures show that the edge sides have a lower $\Delta \mathrm{G}$ than the basal plane (001). This is consistent with $\mathrm{MoB}_{2}$, which has the best activity in the crystal plane (100) [23]. Therefore, exposing the edge sides on the surface of the integral bulk electrode is a good strategy to further optimize the HER performance of $\mathrm{TiB}_{2}, \mathrm{ZrB}_{2}$ and $\mathrm{HfB}_{2}$. 

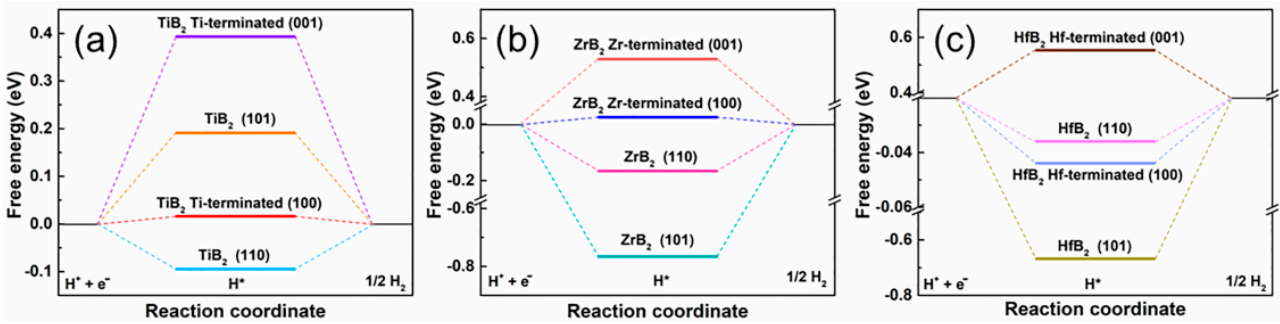

Figure 4. The calculated free-energy diagram (at 25\% hydrogen coverage) for HER over different surfaces of (a) $\mathrm{TiB}_{2}$, (b) $\mathrm{ZrB}_{2}$, (c) $\mathrm{HfB}_{2}$.

$\mathrm{HCl}$ etching is an effective way to modify the surface morphology of TMBs [34]. Thus, the surface of bulk samples $\left(\mathrm{TiB}_{2}, \mathrm{ZrB}_{2}\right.$, and $\left.\mathrm{HfB}_{2}\right)$ are etched by $\mathrm{HCl}$. The SEM results exhibit the surface change with different etching times (Figure 5). The nano needle-like morphology appears on the surface of $\mathrm{TiB}_{2}$ with a longer etching time (Figure $5 \mathrm{a}-\mathrm{d}$ ). Additionally, some humps are formed in $\mathrm{ZrB}_{2}$ with an etching time of $6 \mathrm{~h}$ (Figure $5 \mathrm{e}-\mathrm{h}$ ). $\mathrm{HfB}_{2}$ prefers to generate taper morphology after $4 \mathrm{~h}$ etched (Figure $5 \mathrm{i}-\mathrm{k}$ ). All of these morphologies can enlarge the specific area, which is of benefit to HER. Moreover, the XRD indicates all samples' structures are still $\mathrm{AlB}_{2}$-type after etching (PDF card 85-2083, 65-8704 and 65-8677) and with no impurity (Figure 5l).
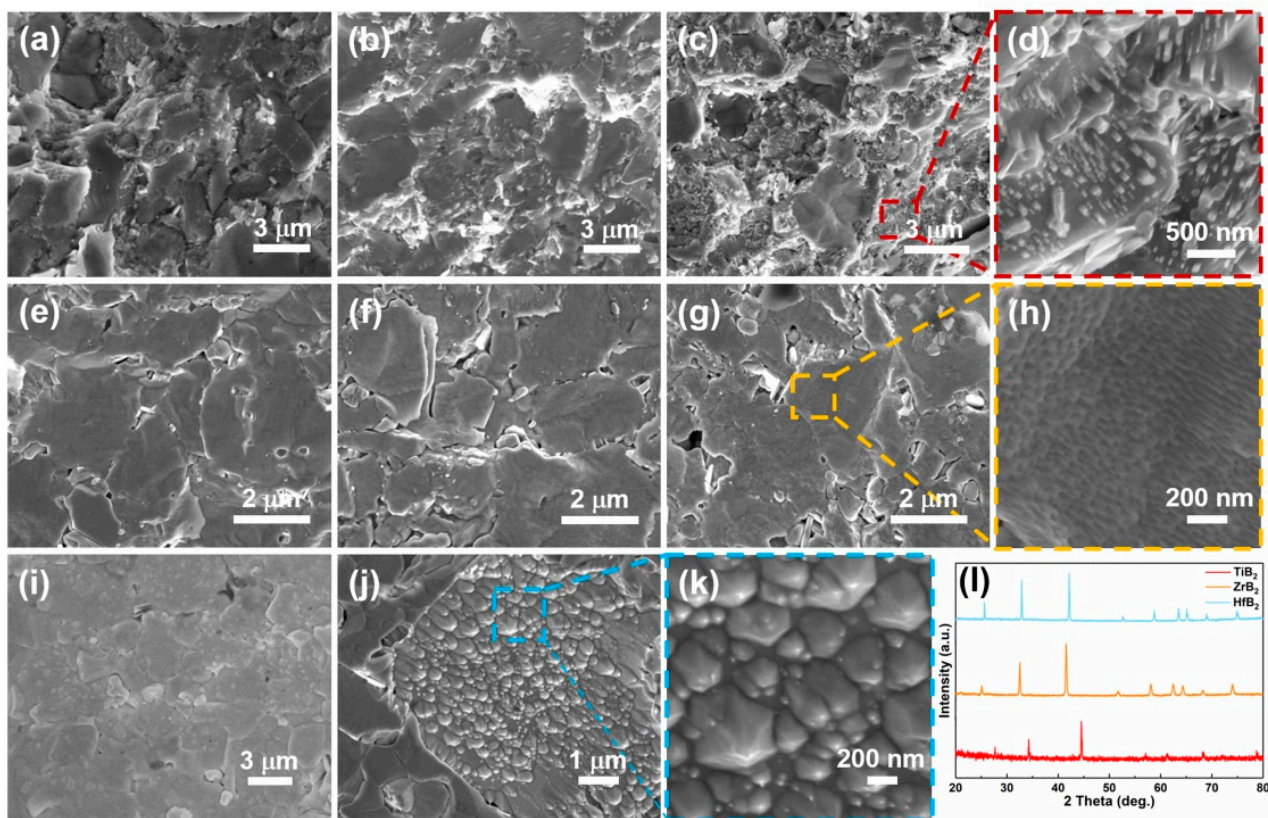

Figure 5. The SEM images of $\mathrm{TiB}_{2}$ after $\mathrm{HCl}$ etched (a) $12 \mathrm{~h}$, (b) $24 \mathrm{~h}$, (c) $48 \mathrm{~h}$, (d) the magnified images of the red dotted box in (c), the SEM images of $\mathrm{ZrB}_{2}$ after $\mathrm{HCl}$ etched (e) $2 \mathrm{~h}$, (f) $4 \mathrm{~h}$, (g) $6 \mathrm{~h}$, (h) the magnified images of the yellow dotted box in (g), the SEM images of $\mathrm{HfB}_{2}$ after $\mathrm{HCl}$ etched (i) $2 \mathrm{~h},(\mathbf{j}) 4 \mathrm{~h}$, (k) the magnified images of the light blue dotted box in (j), (l) the XRD of $\mathrm{TiB}_{2}, \mathrm{ZrB}_{2}$ and $\mathrm{HfB}_{2}$ after $\mathrm{HCl}$ etched.

According to HRTEM (Figure 6a,b), the crystal plane (001) can be found in the needle of $\mathrm{TiB}_{2}$, and the (001) is perpendicular to the direction of along the needle, which is consistent with before results that the direction along the needle is [001] [34]. These results also confirmed that the edge sides of the needle morphology are the edge sides of the structure. The preliminary research confirmed the corrosion mechanism of $\mathrm{AlB}_{2}$-type structures [34], thus the same exposed crystal planes in $\mathrm{ZrB}_{2}$ and $\mathrm{HfB}_{2}$. Therefore, the nano morphology with exposed edge sides was fabricated in some special crystal planes of $\mathrm{TiB}_{2}, \mathrm{ZrB}_{2}$ and $\mathrm{HfB}_{2}$ (Figure 6c). 

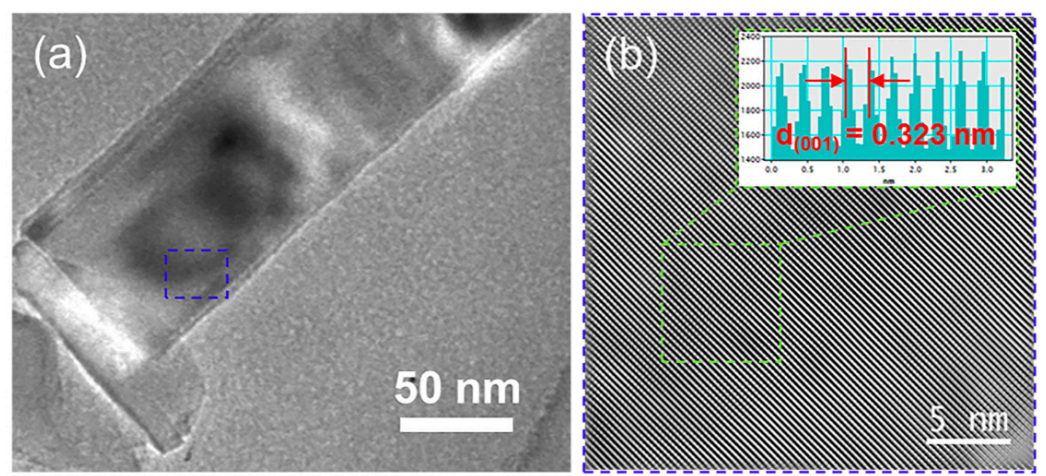

(c)

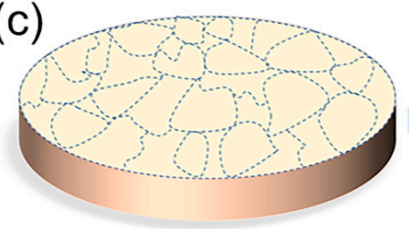

$\mathrm{HCl}$ etching

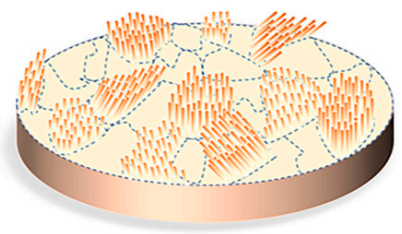

Figure 6. (a) The TEM image of $\mathrm{TiB}_{2}$ nanorod, (b) the HRTEM image of $\mathrm{TiB}_{2}$ needle, (c) schematic diagram of sample surface morphology before and after $\mathrm{HCl}$ etched.

The XPS results before and after $\mathrm{HCl}$ etching are shown in Figure 7. Except for normal states of TMBs at lower binding energy, metal oxides states and boron oxides states with high binding energy on the surface of $\mathrm{TiB}_{2}, \mathrm{ZrB}_{2}$ and $\mathrm{HfB}_{2}$ are observed [43]. However, the oxides states are weaker after $\mathrm{HCl}$ etching. The $\mathrm{HCl}$ corrodes the surface of TMBs by destroying the boron atoms and transition metal atoms, but after corrosion, the remaining surface still maintains the atomic states of TMBs. Therefore, the improvement of HER performance is caused by specific areas and exposed edge sides.
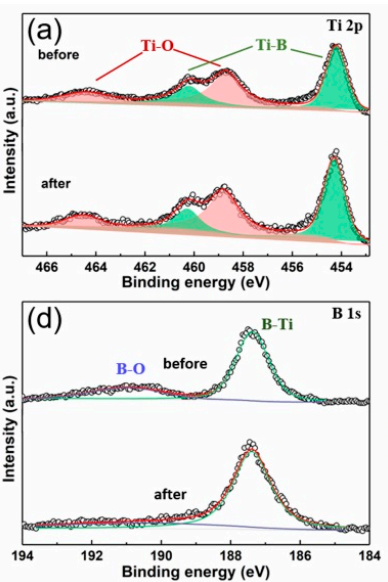
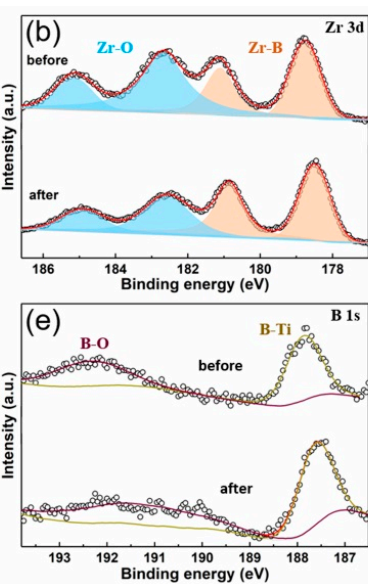
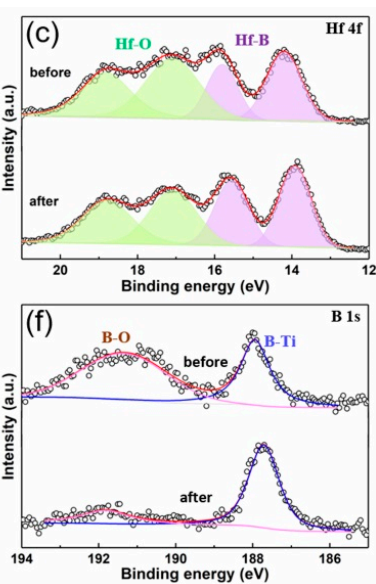

Figure 7. The XPS spectra of $\mathrm{TiB}_{2}$ (a) Ti 2p, (d) B 1s, $\mathrm{ZrB}_{2}$ (b) $\mathrm{Zr} 3 \mathrm{~d}$, (e) B 1s and $\mathrm{HfB}_{2}$ (c) Hf 4f, (f) B 1s before and after $\mathrm{HCl}$ etched.

Uncovering the HER performance of integral bulk electrodes of $\mathrm{TiB}_{2}, \mathrm{ZrB}_{2}$ and $\mathrm{HfB}_{2}$ with nano morphology is urgent. Therefore, the electrochemical activity of $\mathrm{TiB}_{2}, \mathrm{ZrB}_{2}$ and $\mathrm{HfB}_{2}$ with different etching times were measured in $0.5 \mathrm{M} \mathrm{H}_{2} \mathrm{SO}_{4}$ solution. In $0.5 \mathrm{M} \mathrm{H}_{2} \mathrm{SO}_{4}$ solution, the LSV curves of $\mathrm{TiB}_{2}$ give overpotentials of $477,434,346$ and $390 \mathrm{mV}$ at current densities of $10 \mathrm{~mA} \mathrm{~cm}^{-2}$ with etching times of $0,12,24$ and $48 \mathrm{~h}$, respectively (Figure 8a). The optimal etching time is $24 \mathrm{~h}$ in $\mathrm{TiB}_{2}$. Meanwhile, $\mathrm{ZrB}_{2}$ needs $627,598,542$ and $586 \mathrm{mV}$ to get to $10 \mathrm{~mA} \mathrm{~cm}^{-2}$ with etching times of $0,2,4$ and $6 \mathrm{~h}$, respectively (Figure 8e). Additionally, $\mathrm{HfB}_{2}$ also needs higher overpotentials of 563,515 and $518 \mathrm{mV}$ to get to $10 \mathrm{~mA} \mathrm{~cm}^{-2}$ with etching times of 0,2 and $4 \mathrm{~h}$, respectively (Figure $8 \mathrm{i}$ ). Those results are substantially better than the initial powder and the integral bulk electrodes before $\mathrm{HCl}$ 
etching. The HER performance of three structures is firstly improved and then becomes worse after increasing the etching time. Therefore, these structures have the optimal HER performance with different etching times. The structures can exhibit hydrophobicity with longer time $\mathrm{HCl}$ etching [34], which is the reason for worse HER performance with too much etching time. Figure 8b,f,j shows the Tafel plots of $\mathrm{TiB}_{2}, \mathrm{ZrB}_{2}$ and $\mathrm{HfB}_{2}$ with different etching times. The Tafel slope also indicates that $\mathrm{TiB}_{2}, \mathrm{ZrB}_{2}$ and $\mathrm{HfB}_{2}$ have the lowest slope when etching for 24,4 and $2 \mathrm{~h}$, respectively, which means the fastest catalytic reaction rate. The results of EIS and ECSA confirmed that the charge transport resistance of the catalysts decreases and the exposed surface area increases during different $\mathrm{HCl}$ etched times, which are beneficial for $\mathrm{HER}$. The optimal $\mathrm{HCl}$ etched times of $\mathrm{TiB}_{2}, \mathrm{ZrB}_{2}$ and $\mathrm{HfB}_{2}$ also are 24, 4 and $2 \mathrm{~h}$, respectively. All the results indicate that $\mathrm{HCl}$ etching is an effective route to enhance TMBs catalyst for HER performance. Compared with commercial powder, the HER performance of $\mathrm{TiB}_{2}, \mathrm{ZrB}_{2}$ and $\mathrm{HfB}_{2}$ are improved by about $61.9 \%, 40.3 \%$, and $43.6 \%$, respectively, after $\mathrm{HCl}$ etching. The better HER performance arises from better conductivity of the integral bulk electrode with $\mathrm{HCl}$ etching. The nano morphology enlarges the specific area, and the exposed edge sides of structures expose much more activity sites. The HER performance is superior to other $\mathrm{TiB}_{2}, \mathrm{ZrB}_{2}$ and $\mathrm{HfB}_{2}$, even better than some nanosized materials (Table S1). Therefore, this strategy for integral bulk electrodes with nano morphology is an effective way to optimize the HER performance.
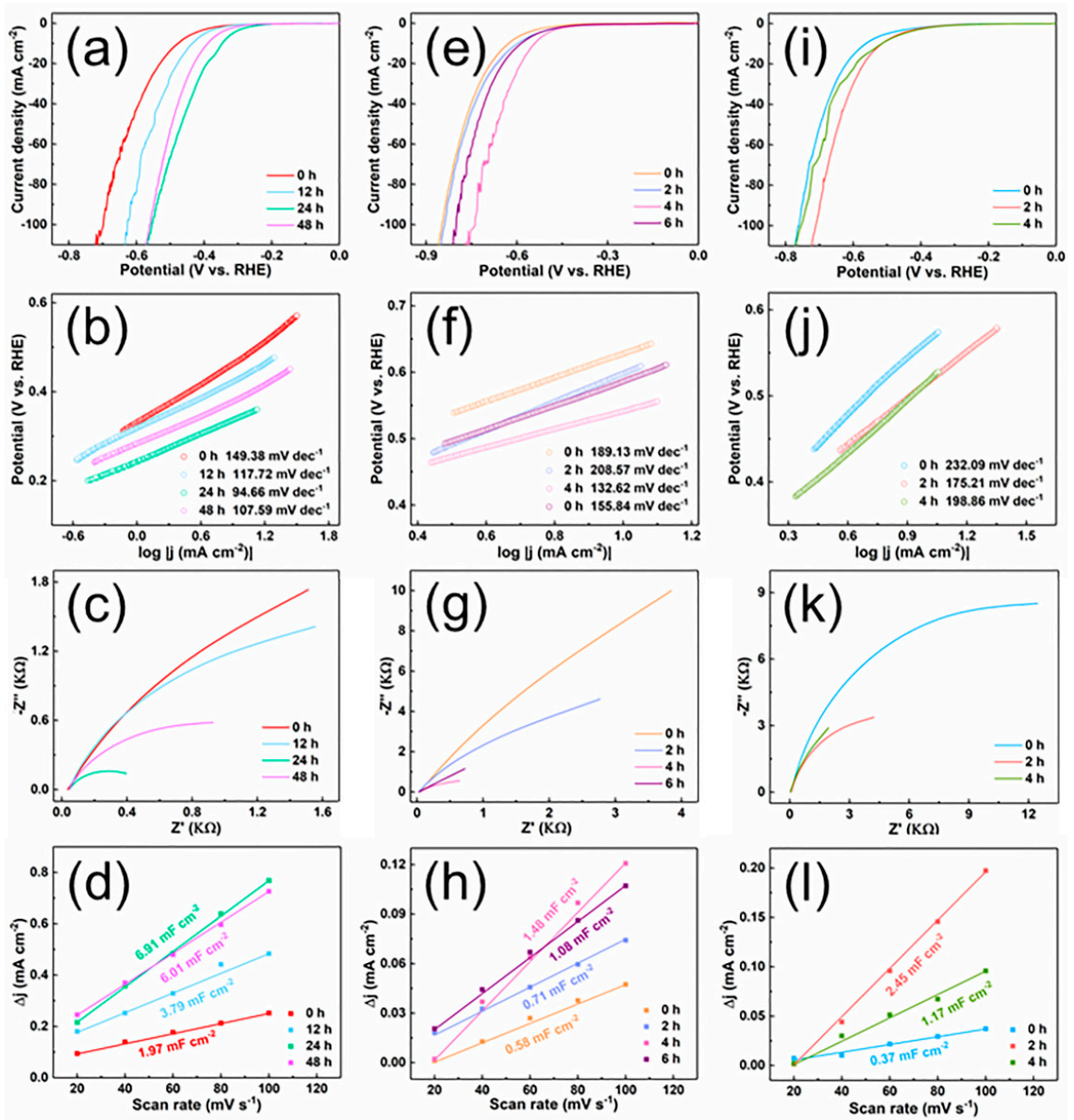

Figure 8. The LSV curves of (a) $\mathrm{TiB}_{2}$, (e) $\mathrm{ZrB}_{2}$, (i) $\mathrm{HfB}_{2}$ with different etched time for HER in $0.5 \mathrm{M} \mathrm{H}_{2} \mathrm{SO}_{4}$ solution, the tafel slopes of (b) $\mathrm{TiB}_{2}$, (f) $\mathrm{ZrB}_{2}$, (j) $\mathrm{HfB}_{2}$ with different etched time, EIS Nyquist plots of (c) $\mathrm{TiB}_{2},(\mathbf{g}) \mathrm{ZrB}_{2},(\mathbf{k}) \mathrm{HfB}_{2}$ with different etched time, ECSA fitting curves of (d) $\mathrm{TiB}_{2}$, (h) $\mathrm{ZrB}_{2}$, (l) $\mathrm{HfB}_{2}$ with different etched time. 


\section{Materials and Methods}

\subsection{Materials}

The powder of $\mathrm{TiB}_{2}(99 \%), \mathrm{ZrB}_{2}(99.5 \%)$ and $\mathrm{HfB}_{2}(99 \%)$ were purchased from Aladdin (Shanghai Aladdin Biochemical Technology Co., Ltd., Shanghai, China). Sulfuric acid (98\%), hydrochloric acid (37\%) and silver paste were purchased from Beijing Chemical Factory (Beijing, China). All reagents were not purified before being used. Highly purified water (>18 $\mathrm{M} \Omega \mathrm{cm}$ resistivity) was provided by a PALL PURELAB Plus system (Sichuan Delishi Technology Co., Ltd., Chengdu, China). The experimental flow chart is shown in Figure 9.

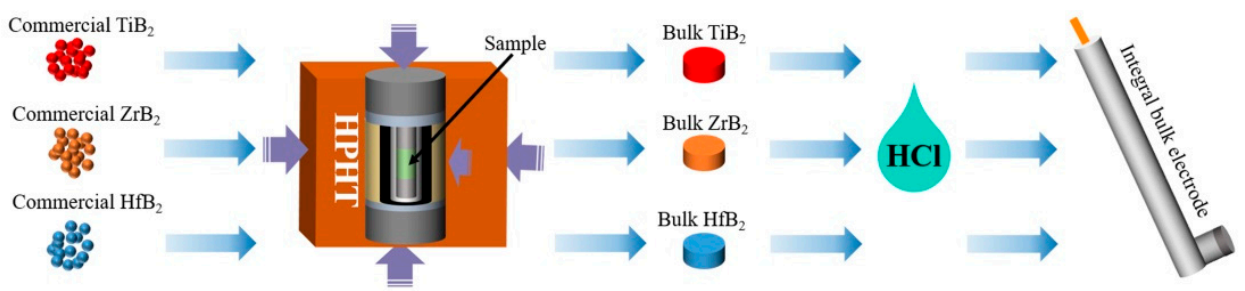

Figure 9. The experimental flow chart. (Preparation process and HER diagram of $\mathrm{TiB}_{2}, \mathrm{ZrB}_{2}$ and $\mathrm{HfB}_{2}$.).

\subsection{Preparation of $\mathrm{TiB}_{2}, \mathrm{ZrB}_{2}$ and $\mathrm{HfB} \mathrm{B}_{2}$ Bulk Materials}

The preparation of bulk materials was consistent with our previous work [34]. Briefly, the sample powders were cold-pressed into a tablet shape with a diameter of $4 \mathrm{~mm}$ and thickness of $2.5 \mathrm{~mm}$. Subsequently, the tablets samples were placed in a cubic anvil apparatus $(6 \times 14,400 \mathrm{KN})$ under the pressure of $5 \mathrm{GPa}$; the temperature was $1600^{\circ} \mathrm{C}$ for $30 \mathrm{~min}, 3 \mathrm{~h}$ and $5 \mathrm{~h}$ for $\mathrm{ZrB}_{2}, \mathrm{HfB}_{2}$, and $\mathrm{TiB}_{2}$, respectively.

\subsection{Constructed the Surface Morphology of $\mathrm{TiB}_{2}, \mathrm{ZrB}_{2}$ and $\mathrm{HfB}_{2}$ Bulk Materials}

The bulk samples were etched in concentrated hydrochloric acid (12 M) for different times. $\mathrm{TiB}_{2}$ was etched for $12,24,48 \mathrm{~h}, \mathrm{ZrB} 2$ was etched for 2, 4, $6 \mathrm{~h}$, and $\mathrm{HfB}_{2}$ was etched for 2, $4 \mathrm{~h}$. After etching, the surface of the sample was thoroughly rinsed with deionized water to remove the residual acid and finally dried in a vacuum oven at $60{ }^{\circ} \mathrm{C}$ overnight.

\subsection{Characterization}

The powder X-ray diffraction (XRD) was performed by a Rigaku D/Max 2550 X-ray diffractometer operating with $\mathrm{Cu} \mathrm{K} \alpha \mathrm{X}$-ray radiation $(\lambda=1.5418 \AA)$. The scanning electron microscope (SEM) images were obtained with an FEI Magellan 400L microscope operating at $18 \mathrm{KV}$. A high-resolution transmission electron microscope (HRTEM) was obtained with a JEM-2200FS TEM operating at 200 KV. The X-ray Photoelectron Spectroscopy (XPS) were recorded on an ESCALAB 250 analyzer with $\mathrm{Al} \mathrm{K \alpha}$ radiation. All the peaks were corrected by $\mathrm{C} 1 \mathrm{~s}$ line at $284.8 \mathrm{eV}$ as standard, and curve fitting and background subtraction were accomplished.

\subsection{Preparation of the Working Electrode}

Powder material. The preparation of the electrode was similar to that previously reported in the literature [44]: $2 \mathrm{mg}$ powder material was dispersed in isopropanol $(200 \mu \mathrm{L})$ and then ultrasonicated for $20 \mathrm{~min}$ to obtain a homogeneous ink. Drop-casting $2 \mu \mathrm{L}$ of homogeneous ink onto a glassy carbon electrode with a diameter of $3 \mathrm{~mm}$, and finally coating the dried samples with $2 \mu \mathrm{L}$ of $0.3 \%$ Nafion solution and letting to dry. The mass loading of the materials was $0.28 \mathrm{mg} \mathrm{cm}^{-2}$.

Bulk material. The preparation of the electrode was similar to that previously reported in the literature [23]: the bulk material was fixed on an L-type copper electrode with conductive silver paste. After the paste was dried, the copper electrode and exposed silver paste were sealed with a modified acrylate adhesive. The effective area of the working electrode was measured with the Leica M125 C system. 


\subsection{Electrochemical Measurement}

All electrochemical measurements were performed with a typical three-electrode system in $0.5 \mathrm{M} \mathrm{H}_{2} \mathrm{SO}_{4}$ using a $\mathrm{CH}$ Instrument (Model 760E). The electrolyte was purged with high-purity $\mathrm{N}_{2}$ gas. A carbon rod and a saturated calomel electrode (SCE) were employed as the counter electrode and reference electrode, respectively. The overpotential is expressed as the value versus the reversible hydrogen electrode (RHE) in this work, according to $\mathrm{E}_{\mathrm{vs} . \mathrm{RHE}}=\mathrm{E}_{\mathrm{vs} . \mathrm{SCE}}+0.241$. For the LSV measurements, the scan rate was set to $1 \mathrm{mV} \mathrm{s}^{-1}$. All of the data were without $i R$ correction in this work. In order to probe the electrochemical double-layer capacitance of the material, cyclic voltammetry (CV) was used at non-Faradaic overpotentials as the means for estimating the effective electrochemical surface areas. With this procedure, a series of $\mathrm{CV}$ measurements were performed at various scan rates $\left(20,40,60,80,100 \mathrm{mV} \mathrm{s}^{-1}\right.$, etc.) from -0.2 to $-0.3 \mathrm{~V}$ vs. RHE region, in which the sweep segments were set to 40 to ensure consistency. By plotting the difference of current density (J) between the anodic and cathodic sweeps ( $\mathrm{J}_{\text {anodic }}-\mathrm{J}_{\text {cathodic }}$ ) at $-0.25 \mathrm{~V}$ vs. RHE against the scan rate, a linear trend was observed. The slope of the fitting line is equal to twice the geometric double-layer capacitance $\left(C_{\mathrm{dl}}\right)$, which is proportional to the cyclic voltammetry $(\mathrm{CV})$ was used at non-faradaic overpotentials as the means for estimating the effective electrochemical surface areas. The slope of the fitting line was equal to twice the geometric double-layer capacitance $\left(\mathrm{C}_{\mathrm{dl}}\right)$, which was proportional to the electrochemically active surface area (ECSA) of the material.

Electrochemical Impedance Spectroscopy (EIS) on the different materials were performed at a potential of $-0.25 \mathrm{~V}$ versus RHE. A sinusoidal voltage with an amplitude of $5 \mathrm{mV}$ and scanning frequency ranging from $10^{5} \mathrm{~Hz}$ to $1 \mathrm{~Hz}$ was applied to carry out the measurements.

\subsection{DFT Calculations}

The density functional theory (DFT) computations were performed by employing the generalized gradient approximation (GGA) in the form of the Perdew-Burke-Ernzerhof for the exchange-correlation functional within the Cambridge Serial Total Energy Package (CASTEP) code $[45,46]$. The cutoff energy for the plane wave calculations and the energy convergence threshold was set to $400 \mathrm{eV}$ and $10^{-4} \mathrm{eV}$, respectively. The residual force was set to less than $0.02 \mathrm{eV} / \AA$. The Brillouin zones were sampled using a Monkhorst-Pack $9 \times 9 \times 9$ and $5 \times 5 \times 1$ k-point grid for all geometric optimization of bulk and slab models, and the $15 \AA$ vacuum layer was used to decouple the periodic images [39].

The value of Gibbs free energy $\left(\Delta \mathrm{G}_{\mathrm{H}^{*}}\right)$ for hydrogen adsorption on the different crystal planes of TMBs can be estimated by

$$
\Delta \mathrm{G}_{\mathrm{H}^{*}}=\Delta \mathrm{E}_{\mathrm{H}^{*}}+\Delta \mathrm{E}_{\mathrm{ZPE}}-\mathrm{T} \Delta \mathrm{S}_{\mathrm{H}^{*}}
$$

Here, $\Delta \mathrm{E}_{\mathrm{ZPE}}$ and $\mathrm{T} \Delta \mathrm{S}_{\mathrm{H}^{*}}$ represent the changes of zero-point energy and entropy of hydrogen adsorption, respectively. In this work, $\Delta \mathrm{E}_{\mathrm{ZPE}}$ is usually very small, about $0.05 \mathrm{eV}$, as previously reported [47]. While $\mathrm{T} \Delta \mathrm{S}_{\mathrm{H}^{*}}$ is obtained by $\mathrm{T} \Delta \mathrm{S}_{\mathrm{H}^{*}} \approx-1 / 2 \mathrm{TS}_{\mathrm{H}_{2}}$, where $\mathrm{S}_{\mathrm{H}_{2}}=130.7 \mathrm{~J} / \mathrm{mol} \cdot \mathrm{K}$ is the entropy of $\mathrm{H}_{2}$ at $298 \mathrm{~K}$ and $1 \mathrm{~atm}$ [40]. Therefore, the equation can be rewritten as $\Delta \mathrm{G}_{\mathrm{H}^{*}}=\Delta \mathrm{E}_{\mathrm{H}^{*}}+0.25 \mathrm{eV}$. $\Delta \mathrm{E}_{\mathrm{H}^{*}}$ is the adsorption energy was calculated by

$$
\Delta \mathrm{EH}_{*}=\mathrm{E}_{[\text {surface }+\mathrm{nH} *]}-\mathrm{E}_{[\text {surface }+(\mathrm{n}-1) \mathrm{H} *]}-1 / 2 \mathrm{E}_{\mathrm{H}_{2}}
$$

Here, $\mathrm{E}_{\left[\text {surface }+\mathrm{nH} \mathrm{H}^{*}\right]}$ and $\mathrm{E}_{\left[\text {surface }+(\mathrm{n}-1) \mathrm{H}^{*}\right]}$ represent the total energy of $\mathrm{n}$ and $(\mathrm{n}-1) \mathrm{H}^{*}$ atoms adsorbed on the surface, respectively. $\mathrm{E}_{\mathrm{H}_{2}}$ is the total energy of a gas phase $\mathrm{H}_{2}$ molecule.

\section{Conclusions}

In conclusion, we reported a new strategy to design high HER performance in TMBs. High-density integral bulk electrodes are composed of $\mathrm{TMBs}\left(\mathrm{TiB}_{2}, \mathrm{ZrB}_{2}\right.$, and $\left.\mathrm{HfB}_{2}\right)$, which indicate better HER performance than commercial powder electrodes. Moreover, nano 
morphology which exposes high active crystal planes, was fabricated in integral bulk electrodes of $\mathrm{TiB}_{2}, \mathrm{ZrB}_{2}$ and $\mathrm{HfB}_{2}$ by $\mathrm{HCl}$ etching. The best $\mathrm{HER}$ of $\mathrm{TiB}_{2}, \mathrm{ZrB}_{2}$ and $\mathrm{HfB}_{2}$ are $346 \mathrm{mV}, 542 \mathrm{mV}, 515 \mathrm{mV}$ at $10 \mathrm{~mA} \mathrm{~cm}^{-2}$, respectively, $61.9 \%, 40.3 \%$, and $43.6 \%$ higher than the commercial powder electrodes. The reasons for better HER performance are the better conductivity of the integral bulk electrode, larger specific area, and much more exposed activity sites. This work is significant to fabricate new high HER performance TMBs.

Supplementary Materials: The following supporting information can be downloaded at: https: / / www.mdpi.com/article/10.3390/catal12020222/s1, Figure S1: The XRD of commercial TiB $2, \mathrm{ZrB}_{2}$, and $\mathrm{HfB}_{2}$; Figure S2: The linear sweep voltammetry (LSV) curves of commercial $\mathrm{TiB}_{2}, \mathrm{ZrB}_{2}$, and $\mathrm{HfB}_{2}$ for HER in $0.5 \mathrm{M} \mathrm{H}_{2} \mathrm{SO}_{4}$ solution; Table S1: Comparison of the catalytic activity of $\mathrm{TiB}_{2}, \mathrm{ZrB}_{2}, \mathrm{HfB}_{2}$ obtained herein with those reported previously. (The Current density is $10 \mathrm{~mA} \mathrm{~cm}^{-2}$.) [48-52].

Author Contributions: Conceptualization, W.Z. and Q.T.; data curation, D.X., Y.C. and X.W.; formal analysis, W.Z., J.C., Q.T. and S.D.; funding acquisition, Q.T. and P.Z.; investigation, W.Z., D.X., Q.T. and P.Z.; methodology, Y.C., C.Y. and Q.T.; project administration, P.Z.; resources, P.Z. and Q.T.; supervision, P.Z.; validation, X.W.; visualization, P.Z.; writing—original draft, W.Z.; writing-review and editing, Y.C., Q.T. and P.Z. All authors have read and agreed to the published version of the manuscript.

Funding: This research was funded by the National Natural Science Foundation of China (under grant Nos. 11904119, 11974131), China postdoctoral Science Foundation (No. 2016M601374), the Open Project of State Key Laboratory of Superhard Materials (Jilin University) (201911), the National Key R\&D Program of China (2018YFA0703400).

Data Availability Statement: All relevant data are contained in the present manuscript.

Conflicts of Interest: The authors declare no conflict of interest.

\section{References}

1. Nielsen, M.; Alberico, E.; Baumann, W.; Drexler, H.-J.; Junge, H.; Gladiali, S.; Beller, M. Low-temperature aqueous-phase methanol dehydrogenation to hydrogen and carbon dioxide. Nature 2013, 495, 85-89. [CrossRef] [PubMed]

2. Hosseini, S.E.; Wahid, M.A. Hydrogen production from renewable and sustainable energy resources: Promising green energy carrier for clean development. Renew. Sustain. Energy Rev. 2016, 57, 850-866. [CrossRef]

3. Wang, X.; Maeda, K.; Thomas, A.; Takanabe, K.; Xin, G.; Carlsson, J.M.; Domen, K.; Antonietti, M. A metal-free polymeric photocatalyst for hydrogen production from water under visible light. Nat. Mater. 2009, 8, 76-80. [CrossRef]

4. Kudo, A.; Miseki, Y. Heterogeneous photocatalyst materials for water splitting. Chem. Soc. Rev. 2009, 38, 253-278. [CrossRef] [PubMed]

5. Li, Y.; Wang, H.; Xie, L.; Liang, Y.; Hong, G.; Dai, H. MoS 2 Nanoparticles Grown on Graphene: An Advanced Catalyst for the Hydrogen Evolution Reaction. J. Am. Chem. Soc. 2011, 133, 7296-7299. [CrossRef]

6. Landman, A.; Dotan, H.; Shter, G.E.; Wullenkord, M.; Houaijia, A.; Maljusch, A.; Grader, G.S.; Rothschild, A. Photoelectrochemical water splitting in separate oxygen and hydrogen cells. Nat. Mater. 2017, 16, 646-651. [CrossRef]

7. Chi, J; Yu, H. Water electrolysis based on renewable energy for hydrogen production. Chin. J. Catal. 2018, 39, 390-394. [CrossRef]

8. Wang, J.; Cui, W.; Liu, Q.; Xing, Z.; Asiri, A.M.; Sun, X. Recent Progress in Cobalt-Based Heterogeneous Catalysts for Electrochemical Water Splitting. Adv. Mater. 2016, 28, 215-230. [CrossRef]

9. Zou, X.; Zhang, Y. Noble metal-free hydrogen evolution catalysts for water splitting. Chem. Soc. Rev. 2015, 44, 5148-5180. [CrossRef]

10. Ledezma-Yanez, I.; Wallace, W.D.Z.; Sebastián-Pascual, P.; Climent, V.; Feliu, J.M.; Koper, M.T.M. Interfacial water reorganization as a $\mathrm{pH}$-dependent descriptor of the hydrogen evolution rate on platinum electrodes. Nat. Energy 2017, 2, 17031. [CrossRef]

11. Arif, M.; Yasin, G.; Shakeel, M.; Mushtaq, M.A.; Ye, W.; Fang, X.; Ji, S.; Yan, D. Highly active sites of NiVB nanoparticles dispersed onto graphene nanosheets towards efficient and pH-universal overall water splitting. J. Energy Chem. 2021, 58, 237-246. [CrossRef]

12. Liu, C.; Gong, T.; Zhang, J.; Zheng, X.; Mao, J.; Liu, H.; Li, Y.; Hao, Q. Engineering $\mathrm{Ni}_{2} \mathrm{P}-\mathrm{NiSe}_{2}$ heterostructure interface for highly efficient alkaline hydrogen evolution. Appl. Catal. B Environ. 2020, 262, 118245. [CrossRef]

13. Anantharaj, S.; Kundu, S.; Noda, S. Progress in nickel chalcogenide electrocatalyzed hydrogen evolution reaction. J. Mater. Chem. A 2020, 8, 4174-4192. [CrossRef]

14. Liu, Y.; Vijayakumar, P.; Liu, Q.; Sakthivel, T.; Chen, F.; Dai, Z. Shining Light on Anion-Mixed Nanocatalysts for Efficient Water Electrolysis: Fundamentals, Progress, and Perspectives. Nano-Micro Lett. 2022, 14, 43. [CrossRef]

15. Lin, Z.; Xiao, B.; Wang, Z.; Tao, W.; Shen, S.; Huang, L.; Zhang, J.; Meng, F.; Zhang, Q.; Gu, L.; et al. Planar-Coordination PdSe 2 Nanosheets as Highly Active Electrocatalyst for Hydrogen Evolution Reaction. Adv. Funct. Mater. 2021, 31, 2102321. [CrossRef] 
16. Wei, Y.; Soomro, R.A.; Xie, X.; Xu, B. Design of efficient electrocatalysts for hydrogen evolution reaction based on 2D MXenes. J. Energy Chem. 2021, 55, 244-255. [CrossRef]

17. Wang, M.; Zhang, L.; He, Y.; Zhu, H. Recent advances in transition-metal-sulfide-based bifunctional electrocatalysts for overall water splitting. J. Mater. Chem. A 2021, 9, 5320-5363. [CrossRef]

18. Theerthagiri, J.; Murthy, A.P.; Lee, S.J.; Karuppasamy, K.; Arumugam, S.R.; Yu, Y.; Hanafiah, M.M.; Kim, H.-S.; Mittal, V.; Choi, M.Y. Recent progress on synthetic strategies and applications of transition metal phosphides in energy storage and conversion. Ceram. Int. 2021, 47, 4404-4425. [CrossRef]

19. Theerthagiri, J.; Lee, S.J.; Murthy, A.P.; Madhavan, J.; Choi, M.Y. Fundamental aspects and recent advances in transition metal nitrides as electrocatalysts for hydrogen evolution reaction: A review. Curr. Opin. Solid State Mater. Sci. 2020, 24,100805 [CrossRef]

20. Zeng, M.; Li, Y. Recent advances in heterogeneous electrocatalysts for the hydrogen evolution reaction. J. Mater. Chem. A 2015, 3, 14942-14962. [CrossRef]

21. Lee, E.; Fokwa, B.P.T. Nonprecious Metal Borides: Emerging Electrocatalysts for Hydrogen Production. Acc. Chem. Res. 2022, 55, 56-64. [CrossRef] [PubMed]

22. Huang, H.; Jung, H.; Jun, H.; Woo, D.Y.; Han, J.W.; Lee, J. Design of grain boundary enriched bimetallic borides for enhanced hydrogen evolution reaction. Chem. Eng. J. 2021, 405, 126977. [CrossRef]

23. Chen, Y.; Yu, G.; Chen, W.; Liu, Y.; Li, G.D.; Zhu, P.; Tao, Q.; Li, Q.; Liu, J.; Shen, X.; et al. Highly Active, Nonprecious Electrocatalyst Comprising Borophene Subunits for the Hydrogen Evolution Reaction. J. Am. Chem. Soc. 2017, 139, 12370-12373. [CrossRef] [PubMed]

24. Zhuang, Z.; Li, Y.; Li, Z.; Lv, F.; Lang, Z.; Zhao, K.; Zhou, L.; Moskaleva, L.; Guo, S.; Mai, L. MoB/g-C $\mathrm{N}_{4}$ Interface Materials as a Schottky Catalyst to Boost Hydrogen Evolution. Angew. Chem. Int. Ed. 2018, 57, 496-500. [CrossRef]

25. Shi, P.; Zhang, Y.; Zhang, G.; Zhu, X.; Wang, S.; Wang, A.-L. A crystalline/amorphous CoP@CoB hierarchical core-shell nanorod array for enhanced hydrogen evolution. J. Mater. Chem. A 2021, 9, 19719-19724. [CrossRef]

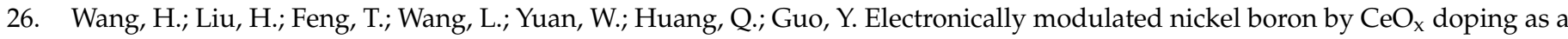
highly efficient electrocatalyst towards overall water splitting. Dalton Trans. 2022, 51, 675-684. [CrossRef]

27. Chen, L.; Wang, Y.; Cheng, S.; Zhao, X.; Zhang, J.; Ao, Z.; Zhao, C.; Li, B.; Wang, S.; Wang, S.; et al. Nitrogen defects/boron dopants engineered tubular carbon nitride for efficient tetracycline hydrochloride photodegradation and hydrogen evolution. Appl. Catal. B Environ. 2022, 303, 120932. [CrossRef]

28. Chen, Z.; Zheng, R.; Graś, M.; Wei, W.; Lota, G.; Chen, H.; Ni, B.-J. Tuning electronic property and surface reconstruction of amorphous iron borides via W-P co-doping for highly efficient oxygen evolution. Appl. Catal. B Environ. 2021, $288,120037$. [CrossRef]

29. Mazanek, V.; Nahdi, H.; Luxa, J.; Sofer, Z.; Pumera, M. Electrochemistry of layered metal diborides. Nanoscale 2018, 10, 11544-11552. [CrossRef]

30. Chen, Y.; Ye, Y.; Tao, Q.; Yang, L.; Cheng, J.; Liu, X.; Cao, J.; Fan, H.; Wei, M.; Zhu, P.; et al. Constructing 1D Boron Chains in the Structure of Transition Metal Monoborides for Hydrogen Evolution Reactions. Catalysts 2021, 11, 1265. [CrossRef]

31. Qian, G.; Chen, J.; Yu, T.; Liu, J.; Luo, L.; Yin, S. Three-Phase Heterojunction NiMo-Based Nano-Needle for Water Splitting at Industrial Alkaline Condition. Nano-Micro Lett. 2022, 14, 20. [CrossRef]

32. Wang, P.; Kumar, R.; Sankaran, E.M.; Qi, X.; Zhang, X.; Popov, D.; Cornelius, A.L.; Li, B.; Zhao, Y.; Wang, L. Vanadium Diboride $\left(\mathrm{VB}_{2}\right)$ Synthesized at High Pressure: Elastic, Mechanical, Electronic, and Magnetic Properties and Thermal Stability. Inorg. Chem. 2018, 57, 1096-1105. [CrossRef] [PubMed]

33. Tao, Q.; Chen, Y.; Lian, M.; Xu, C.; Li, L.; Feng, X.; Wang, X.; Cui, T.; Zheng, W.; Zhu, P. Modulating Hardness in Molybdenum Monoborides by Adjusting an Array of Boron Zigzag Chains. Chem. Mater. 2019, 31, 200-206. [CrossRef]

34. Gan, Q.; Liu, H.; Zhang, S.; Wang, F.; Cheng, J.; Wang, X.; Dong, S.; Tao, Q.; Chen, Y.; Zhu, P. Robust Hydrophobic Materials by Surface Modification in Transition-Metal Diborides. ACS Appl. Mater. Interfaces 2021, 13, 58162-58169. [CrossRef] [PubMed]

35. Wang, W.; Peng, F.; Liang, H.; Guan, S.; Liang, W.; Zhang, L.; Huang, M.; Tang, Y.; He, D. Synthesis and sintering of tungsten tetraboride and tantalum-bearing tungsten tetraboride under ultra high temperature and high pressure. Int. J. Refract. Met. Hard Mater. 2022, 102, 105701. [CrossRef]

36. Jaramillo, T.F.; Jørgensen, K.P.; Bonde, J.; Nielsen, J.H.; Horch, S.; Chorkendorff, I. Identification of Active Edge Sites for Electrochemical $\mathrm{H}_{2}$ Evolution from $\mathrm{MoS}_{2}$ Nanocatalysts. Science 2007, 317, 100-102. [CrossRef] [PubMed]

37. Faber, M.S.; Jin, S. Earth-abundant inorganic electrocatalysts and their nanostructures for energy conversion applications. Energy Environ. Sci. 2014, 7, 3519-3542. [CrossRef]

38. Zhang, X.; Luo, X.; Han, J.; Li, J.; Han, W. Electronic structure, elasticity and hardness of diborides of zirconium and hafnium: First principles calculations. Comput. Mater. Sci. 2008, 44, 411-421. [CrossRef]

39. Chen, Y.; Rong, J.; Wang, Z.; Tao, Q.; Gan, Q.; Wang, F.; Ye, Y.; Liu, X.; Cao, J.; Fan, H.; et al. Tailoring the d-band center by borophene subunits in chromic diboride toward the hydrogen evolution reaction. Inorg. Chem. Front. 2021, 8, 5130-5138. [CrossRef]

40. Jothi, P.R.; Zhang, Y.; Scheifers, J.P.; Park, H.; Fokwa, B.P.T. Molybdenum diboride nanoparticles as a highly efficient electrocatalyst for the hydrogen evolution reaction. Sustain. Energy Fuels 2017, 1, 1928-1934. [CrossRef] 
41. Park, H.; Zhang, Y.; Lee, E.; Shankhari, P.; Fokwa, B.P.T. High-Current-Density HER Electrocatalysts: Graphene-like Boron Layer and Tungsten as Key Ingredients in Metal Diborides. ChemSusChem 2019, 12, 3726-3731. [CrossRef]

42. Jothi, P.R.; Zhang, Y.; Yubuta, K.; Culver, D.; Conley, M.P.; Fokwa, B.P.T. Abundant vanadium diboride with graphene-like boron layers for hydrogen evolution. ACS Appl. Energy Mater. 2019, 2, 176-181. [CrossRef]

43. Moulder, J.F.; Stickle, W.F.; Sobol, P.E.; Bomben, K.D. Handbook of X-ray Photoelectron Spectroscopy; Perkin-Elmer Corporation Physical Electronics Division: Eden Prairie, MN, USA, 1992; p. 261.

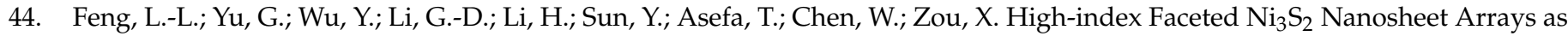
Highly Active and Ultrastable Electrocatalysts for Water Splitting. J. Am. Chem. Soc. 2015, 137, 14023-14026. [CrossRef] [PubMed]

45. Segall, M.D.; Lindan, P.J.D.; Probert, M.J.; Pickard, C.J.; Hasnip, P.J.; Clark, S.J.; Payne, M.C. First-principles simulation: Ideas, illustrations and the CASTEP code. J. Phys. Condens. Matter 2002, 14, 2717-2744. [CrossRef]

46. Li, Y.; Gao, Y.; Xiao, B.; Min, T.; Yang, Y.; Ma, S.; Yi, D. The electronic, mechanical properties and theoretical hardness of chromium carbides by first-principles calculations. J. Alloys Compd. 2011, 509, 5242-5249. [CrossRef]

47. Tang, Q.; Jiang, D.-D. Mechanism of Hydrogen Evolution Reaction on 1T-MoS 2 from First Principles. ACS Catal. 2016, 6, 4953-4961. [CrossRef]

48. Zheng, S.; Fu, Y.; Zheng, L.; Zhu, Z.; Yu, G.; Yang, D. Polypyrrole encapsulating $\mathrm{TiB}_{2}$ as newly-emerged electrocatalyst for highly boosted hydrogen evolution reaction. Ceram. Int. 2019, 45, 23298-23303. [CrossRef]

49. Li, Q.; Zou, X.; Ai, X.; Chen, H.; Sun, L.; Zou, X. Revealing Activity Trends of Metal Diborides Toward pH-Universal Hydrogen Evolution Electrocatalysts with Pt-Like Activity. Adv. Energy Mater. 2019, 9, 1803369. [CrossRef]

50. Lim, C.S.; Sofer, Z.; Mazánek, V.; Pumera, M. Layered titanium diboride: Towards exfoliation and electrochemical applications. Nanoscale 2015, 7, 12527-12534. [CrossRef]

51. Sitler, S.J.; Raja, K.S.; Charit, I. Z ZrB $2-\mathrm{HfB}_{2}$ Solid Solutions as Electrode Materials for Hydrogen Reaction in Acidic and Basic Solutions. Mater. Lett. 2017, 188, 239-243. [CrossRef]

52. Mete, B.; Peighambardoust, N.S.; Aydin, S.; Sadeghi, E.; Aydemir, U. Metal-substituted zirconium diboride $\left(\mathrm{Zr}_{1-\mathrm{x}} \mathrm{TM} \times \mathrm{x} \mathrm{B}_{2} ; \mathrm{TM}=\mathrm{Ni}\right.$, $\mathrm{Co}$, and $\mathrm{Fe}$ ) as low-cost and high-performance bifunctional electrocatalyst for water splitting. Electrochim. Acta 2021, $389,138789$. [CrossRef] 